\title{
Detection of infectious salmon anaemia virus (ISAV) by RT-PCR after cohabitant exposure in Atlantic salmon Salmo salar
}

\author{
Aase B. Mikalsen ${ }^{1}$, Ann Teig ${ }^{1}$, Anne-Lill Helleman ${ }^{2}$, Siri Mjaaland ${ }^{1}$, Espen Rimstad ${ }^{1, *}$ \\ ${ }^{1}$ Department of Pharmacology, Microbiology and Food Hygiene, The Norwegian School of Veterinary Science, \\ PO Box 8146, Dep., 0033 Oslo, Norway \\ ${ }^{2}$ GenoMar asa, Oslo Research Park, Gaustadalléen 21, 0349 Oslo, Norway
}

\begin{abstract}
A reverse transcription polymerase chain reaction (RT-PCR) was used to study the early phase of infectious salmon anaemia virus (ISAV) infection in Atlantic salmon Salmo salar L. The detection threshold for the RT-PCR was estimated to be 0.01 to 0.1 TCID $_{50}$. A protocol that closely mimics the conditions in populations of farmed salmon was used. The major port of ISAV entry was most likely the gills, but oral entry could not be excluded. The gills and heart were RT-PCR positive $5 \mathrm{~d}$ post infection and there was a rapid viraemic spread of the virus after entry. Ten or more days post infection, most organs yielded RT-PCR positive samples. The viral load of the fish followed a 2-phase curve with the first maximum at approximately $15 \mathrm{~d}$ and a minimum around $25 \mathrm{~d}$. After $25 \mathrm{~d}$, there was a steady increase in viral load until all sampled organs eventually became positive. In an experiment in which the transportation of material from field to diagnostic laboratory was simulated, the transportation of whole fish was found to be optimal for the performance of RT-PCR.
\end{abstract}

KEY WORDS: Infectious salmon anaemia virus $\cdot$ ISAV $\cdot$ RT-PCR $\cdot$ Detection of ISAV

\section{INTRODUCTION}

Infectious salmon anaemia (ISA) is a multisystem disease recognized in farmed Atlantic salmon Salmo salar L. in Norway, Canada and Scotland (Thorud \& Djupvik 1988, Mullins et al. 1998, Rodger et al. 1998). The disease may cause a rapid, dramatic increase in mortality in affected fish, but occasionally, the fish exhibit reduced weight gain, a dizzy appearance and a slow increase in mortality. The diagnosis of ISA has been based mainly on clinical observations and typical changes in gross pathology, histopathology and haematology, and by antigen detection tests on frozen tissue sections (Evensen et al. 1991, Falk \& Dannevig 1995). More recently, RT-PCR has been introduced (Rimstad et al. 1999, Devold et al. 2000). Although the pathological changes found in ISA-affected fish are typical in most cases, there are variations such as the predominant hepatic changes described in classical ISA (Evensen et al. 1991), while renal changes have been

${ }^{*}$ Corresponding author. E-mail: espen.rimstad@veths.no prominent in some recent ISA outbreaks (Rodger \& Richards 1998). The differences in clinical appearance and pathology are probably related to properties of the infectious agent, infectious salmon anaemia virus (ISAV), and/or of the host and/or environmental factors. Confirmative detection methods such as RT-PCR in addition to pathological examination are therefore beneficial tools for the diagnosis of ISAV.

Currently there is no commercial vaccine or treatment available for ISA. Therefore, control of the disease has been based on reducing exposure of farmed salmon to ISAV. The properties of ISAV that have been described so far have all been in concordance with properties of members of the Orthomyxoviridae (Falk et al. 1997, Mjaaland et al. 1997, Krossoy et al. 1999, Rimstad et al. 1999, 2001, Sandvik et al. 2000). However, phylogenetically, ISAV is only distantly related to mammalian or avian orthomyxoviruses (Mjaaland et al. 1997, Krossoy et al. 1999). The mammalian orthomyxoviruses induce acute respiratory diseases. The virus is present in the animal for a limited period of time, and there is no persistent carrier state of these 
viruse in their hosts. However, there are indications that ISAV can cause long-term infection, based on observations in farms with infected fish, and also in experimental settings (Nylund \& Jakobsen 1995). Screenings and surveys of ISAV infection in salmon with a clinically healthy appearance would require a highly sensitive detection method as it can be expected that the viral load in such fish would be low.

There have been some studies of the early pathological changes in ISA (Falk et al. 1995, Speilberg et al. 1995). However these studies have been based on experiments in which fish have been injected intraperitoneally with ISAV. The initial phase of a primary ISAV infection in Atlantic salmon resulting from a natural route of infection is not well described. The primary target organs of ISAV and the rate with which the infection spreads in a host are not known. However, in the initial phase of a natural ISAV infection, i.e. soon after the introduction of the virus to a farm, the infectious dose that the individual fish would be exposed to and the viral load in the infected fish would presumably be low, and present diagnostic procedures may not be sufficiently sensitive to detect these low levels.

To address the problem of a sensitive diagnostic procedure for ISAV, an RT-PCR procedure was optimised and used to monitor the early spread of ISAV within its host after cohabitant infection.

\section{MATERIALS AND METHODS}

Experimental infections. Atlantic salmon presmolts with an average weight of approximately $40 \mathrm{~g}$ were used in the experimental infections. The fish originated from a hatchery where ISA had never been diagnosed. During the experiments, the fish were kept in fresh water at 8 to $10^{\circ} \mathrm{C}$ in $150 \mathrm{l}$ tanks with a water flow of $11 \mathrm{~min}^{-1}$. All samples were aseptically removed, and tissue from the heart, gills, liver, spleen and midkidney from each fish was placed in separate tubes and, except for Trial IV, immediately frozen at $-70^{\circ} \mathrm{C}$. Special care was taken to avoid cross-contamination during sampling. The Glesvaer strain of ISAV was used in all experiments (Mjaaland et al. 1997).

Trial I: A total of 250 fish with 125 fish in each of 2 tanks were used in this trial. At Day 0, 5 fish from each tank were labelled by fin cutting and given an intraperitoneal injection with $0.3 \mathrm{ml}$ diluted cell culture supernatant from ISAV-infected SHK-cells containing a total of $0.3 \times 10^{3} \mathrm{TCID}_{50}$. Tissue samples were collected from 5 fish from each tank at Day 0 prior to adding the ISAV-injected fish and tissues were subsequently collected from 5 fish from each tank at Days 5 , $10,15,20,25,30,35,40,45,49,56$ and 70 .

Trial II: Thirty fish were kept in 1 tank and 5 of these fish were labelled and injected with ISAV as in Trial I at Day 0. Tissue samples were collected from 5 fish prior to adding the ISAV-injected fish and at 24,48, 72 and $96 \mathrm{~h}$ after addition.

Trial III: Thirty fish were kept in 1 tank and $1.5 \times$ $10^{3} \mathrm{TCID}_{50}$ of ISAV was added directly to the water at Day 0. Tissue samples were collected from 5 fish from each tank prior to adding ISAV and at 2, 6, 24, 48 and $72 \mathrm{~h}$ after addition of the virus. In this trial, tissue samples were collected from the intestine in addition to the standard organs.

Trial IV: Seventy-five fish were kept in 1 tank and 5 of these fish were labelled and injected with ISAV as in Trial I at Day 0. From Day 14, tissue samples were collected from 2 cohabitant fish twice weekly and the tissues were tested for the presence of ISAV by RT-PCR. On Day 29, all tissues from the 2 sampled fish were RT-PCR positive. Groups of 5 fish were then collected and processed to simulate different modes of transportation from the field to the diagnostic laboratory. The collection protocol is displayed in Fig. 1. In Groups A to C, whole fish were placed in separate bags, while in Groups D to I organs were aseptically collected from each fish and placed in separate tubes.

Standard RT-PCR. The following different steps in the RT-PCR procedure were optimised before a standard method was established: homogenisation of tissue, RNA extraction methods, amounts of RNA added to the $\mathrm{RT}$ reaction, DNase treatment prior to $\mathrm{RT}$ reaction,
Fig. 1. Groups of 5 fish were sampled and processed to simulate different modes of transportation from the field to the diagnostic laboratory. (a) In Groups A to $\mathrm{C}$, whole fish were 'transported'; (b) in Groups D to I, organs were 'transported'
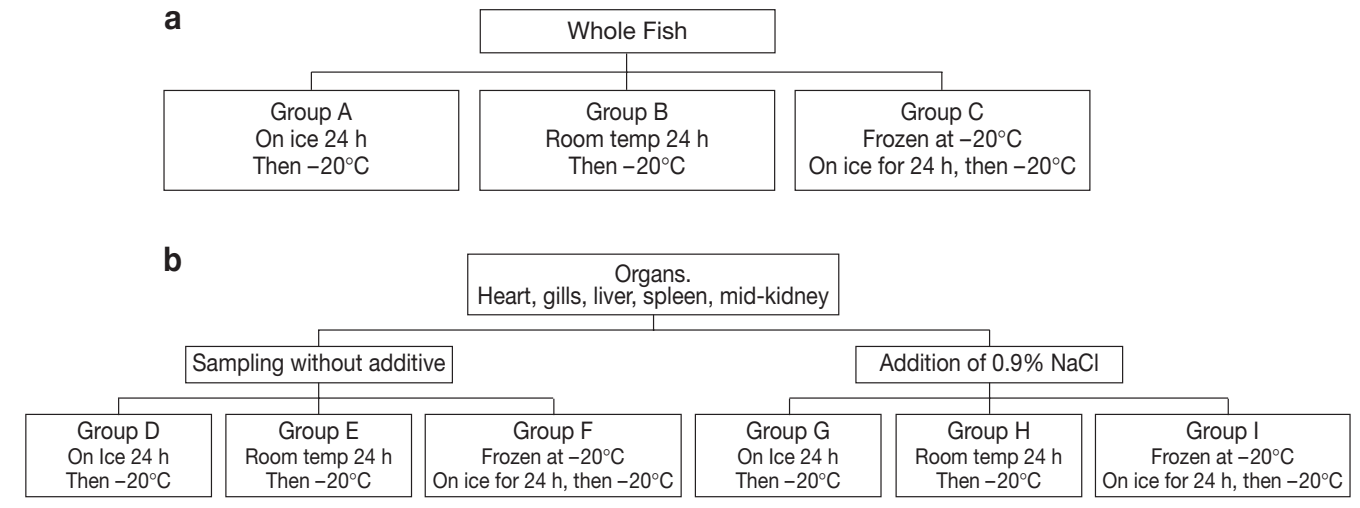
$\mathrm{MgCl}_{2}$ concentration, cycling conditions of time and temperature, 2-tube RT-PCRs versus 1-tube RT-PCRs.

Tissue samples were thawed on ice and homogenized in DEPC-treated phosphate buffered saline (PBS) $(10 \times$ volume of tissue sample weight) in sterile plastic bags, using a roller. From this suspension, $400 \mu \mathrm{l}$ were mixed with $800 \mu \mathrm{l}$ TRIzol $^{\circledR}$ and RNA extracted according to the manufacturer's instructions. The RNA was dissolved in 20 to $200 \mu \mathrm{l}$ DEPC-treated water and the concentration and purity of the RNA were estimated by measuring the optical density at $260 \mathrm{~nm}\left(\mathrm{OD}_{260}\right)$ and the $\mathrm{OD}_{260} / \mathrm{OD}_{280}$ ratio, respectively.

One-step RT-PCR was carried out using Ready-To-Go ${ }^{\circledR}$ RT-PCR Beads (Amersham Pharmacia, Uppsala, Sweden). Random hexamers (pd $[\mathrm{N}]_{6}$ Amersham Pharmacia) were used as primers for the cDNA synthesis and ISAVspecific primer pair-targeting genomic segment 8 was used for the PCR amplification (Mjaaland et al. 1997; length of product: $155 \mathrm{bp}$ ). To verify results, a primer pair targeting the ISAV genomic segment encoding hemagglutinin was used (forward primer: ACTTGGGAACCAATGACTGC, reverse primer: CTTCACCGAAAAACCGGTAA; length of product: $194 \mathrm{bp}$ ) (Rimstad et al. 2001). From each sample, $2 \mu \mathrm{g}$ RNA was added and incubated at $42^{\circ} \mathrm{C}$ for $30 \mathrm{~min}$ for the cDNA synthesis. To avoid non-specific reactions in the cDNA synthesis, the ISAV specific primers were added after the cDNA synthesis had terminated, with the tubes kept on ice. Cycling conditions were $94^{\circ} \mathrm{C}$ for $5 \mathrm{~min}$ followed by 35 cycles of $94^{\circ} \mathrm{C}$ for $30 \mathrm{~s}, 55^{\circ} \mathrm{C}$ for $15 \mathrm{~s}$ and $72^{\circ} \mathrm{C}$ for $30 \mathrm{~s}$ and a final extension at $72^{\circ} \mathrm{C}$ for $7 \mathrm{~min}$. PCR products were resolved by electrophoresis on a $3 \%$ NuSieve 3:1 agarose (FMC Bioproducts, Rockland, ME) and visualized under UV light after ethidium bromide staining. Cloning and sequencing were performed to confirm the ISAV specificity of the PCR product generated using primers binding to the hemagglutinin encoding segment primers, as has been done previously for the segment 8 product (Mjaaland et al. 1997).

For each run, a tissue sample from an ISAV negative fish that went through all steps in the procedure was used as a negative control while RNA from ISAVinfected SHK-1 cell culture, introduced in the RT-step, was used as positive control.

Sensitivity of RT-PCR. To measure the sensitivity of the RT-PCR, a cell culture harvest containing $4 \times$ $10^{5} \mathrm{TCID}_{50} \mathrm{ml}^{-1}$ ISAV was used. Quantification of the virus was performed by seeding SHK-1 cultures with 10 fold dilutions of the cell culture fluid, incubating at $15^{\circ} \mathrm{C}$ for $1 \mathrm{wk}$ and then subsequently staining with the Mab 3H6F8 and secondary anti-mouse antibodies for immunofluorescent staining (Falk et al. 1998). The viruscontaining cell culture fluid was then diluted 10 -fold and each dilution was mixed with a tissue suspension from a negative control fish. After RNA extraction, $2 \mu \mathrm{g}$ RNA from each tissue suspension was tested by RT-PCR.

\section{RESULTS}

\section{Optimisation of RT-PCR detection of ISAV infection}

The standard RT-PCR procedure was a result of an optimisation of the method. The following comments can be made:

(1) Treatment of the extracted total RNA with RNasefree DNase did not increase the sensitivity of the RT$\mathrm{PCR}$, and thus eventual contamination with genomic DNA was not considered to cause problems.

(2) Nonspecific DNA fragments were observed with concentrations other than $1.5 \mathrm{mM} \mathrm{MgCl}_{2}$, which subsequently was chosen as the standard concentration.

(3) When the different RT-PCR methods using the optimised conditions were compared, Ready-To-Go ${ }^{\circledR}$ RT-PCR beads were found to be the most sensitive, giving consistent positive results at $1 \times 10^{-6}$ dilution (Fig. 2b). The other 1-tube method had an end-point dilution at $5 \times 10^{-5}(2 \mathrm{a})$, while the 2 -tube method was less sensitive and showed variable end-point dilutions.
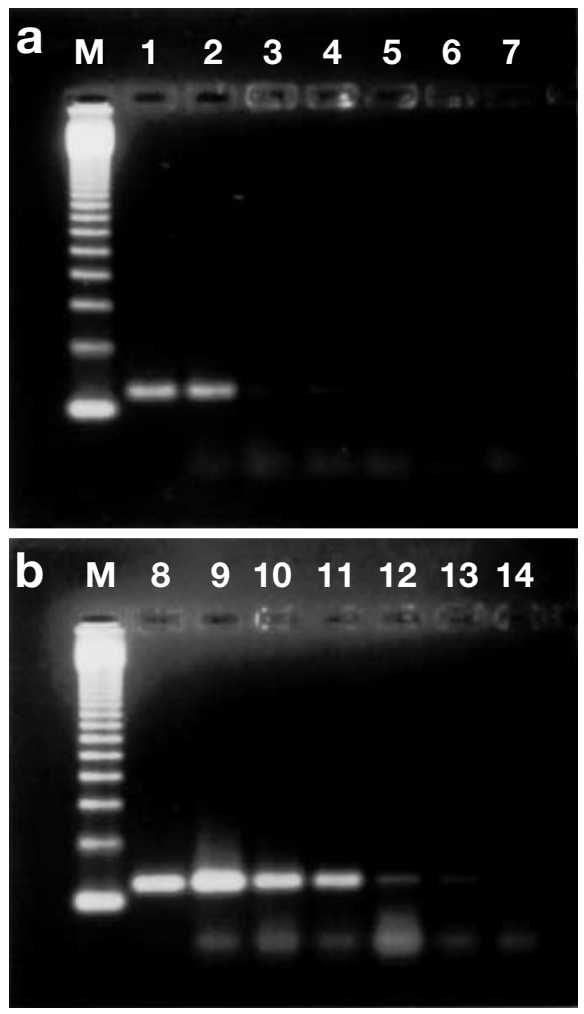

Fig. 2. Comparison of 2 different 1-tube RT-PCR procedures after end-point dilution of target. RT-PCR products were electrophoresed in agarose gel and stained with ethidium bromide. Lane M: molecular size marker (123 basepair ladder, Gibco). (a) Titan ${ }^{\mathrm{TM}}$ One Tube RT-PCR System, Lane 1: $1 \times$ $10^{-3}$; Lane 2: $5 \times 10^{-4}$; Lane 3: $1 \times 10^{-4}$; Lane 4: $5 \times 10^{-5}$; Lane 5: $1 \times 10^{-5}$; Lane 6: $5 \times 10^{-6}$; Lane 7: $1 \times 10^{-6}$. (b) Ready-To-Go ${ }^{\circledR}$ RT-PCR Beads, Lanes 8 to 14: same dilutions of samples as in Lanes 1 to 7 (a), respectively 


\section{Sensitivity of RT-PCR}

The standard RT-PCR had an estimated detection limit between 0.01 and $0.1 \mathrm{TCID}_{50}$. This estimate was based on end-point dilution trials of cell culture fluid containing ISAV in which each dilution was mixed with a tissue suspension from a negative control fish. The 2-tube RT-PCR system was less sensitive, having a limit between 1 and $10 \mathrm{TCID}_{50}$.

\section{Experimental infections}

All tissue samples collected from fish prior to the addition of ISAV to the tanks were negative in RT-PCR.

In infection Trial I, the fish that were injected with ISAV started to die at Day 24 post-injection (p.i.) and all 10 fish died before cohabitating fish died. The cohabitating fish started to die at Day 33. No significant difference in the time distribution of RT-PCR results or clinical appearance or mortality of ISA was observed between the 2 tanks. The fish that were not collected for tissue sampling were all dead by Day 87. The RTPCR results for the different organs from the cohabitating fish in Trial I are shown in Table 1. Hearts and gills were the only RT-PCR positive organs at the first sampling, at trial Day 5. The heart was also the only organ that yielded positive RT-PCR, from some or all fish, in all of the samplings. The liver samples were RT-PCR negative in all of the 10 fish sampled on Days 5 and 25, and mid-kidney samples were RT-PCR negative in all of the 10 fish sampled on Days 5, 20 and 25.

Table 1. RT-PCR results from organs of cohabitating fish in Trial I. The 'Day' column represents the days elapsed after ISAV-injected fish were added to the tank. The number in each organ column represents how many of the 10 samples were RT-PCR positive. The 'Individuals' column displays the total number of fish that produced positive RT-PCR results

\begin{tabular}{|lrrrccc|}
\hline Day & Heart & Gill & Liver & Spleen & Kidney & Individuals \\
\hline 5 & 3 & 5 & 0 & 0 & 0 & 5 \\
10 & 5 & 0 & 4 & 5 & 10 & 10 \\
15 & 10 & 10 & 7 & 10 & 10 & 10 \\
20 & 4 & 0 & 10 & 10 & 0 & 10 \\
25 & 5 & 8 & 0 & 2 & 0 & 9 \\
30 & 2 & 10 & 2 & 2 & 2 & 10 \\
35 & 4 & 2 & 7 & 9 & 3 & 9 \\
40 & 7 & 5 & 6 & 6 & 7 & 8 \\
45 & 9 & 5 & 6 & 6 & 10 & 10 \\
49 & 9 & 7 & 8 & 9 & 9 & 9 \\
56 & 10 & 10 & 10 & 9 & 10 & 10 \\
$70 *$ & 5 & 5 & 5 & 5 & 5 & 5 \\
Sum & 73 & 67 & 65 & 73 & 66 & 105 \\
${ }^{*}$ At Day 70, only 5 fish were sampled & \\
\hline \multicolumn{7}{|c}{} \\
\hline
\end{tabular}

The number of organs that tested ISAV positive by RT-PCR peaked at Day 15 when $94 \%$ of the samples were positive. At this sampling, the liver was the only organ that produced negative samples $(3 / 10$ liver samples were negative) (Fig. 3a). The viral load then decreased until Day 25 when $30 \%$ of all samples were positive. Subsequently, the percentage of positive samples increased until all samples were positive at Day 56 and the level remained at $100 \%$ until the end of the experiment. This 2-phase shape of the curve was also typical when RT-PCR results for each organ were displayed separately (Fig. 3b shows results for the heart).

In Trial II, fish were collected at Days 1, 2, 3 and 4 to test whether ISAV could be detected in the fish before Day 5, which was the first sampling day in Trial I. The same organs were tested as in trial $I_{i}$ however, no positive RT-PCR was found.

In Trial III, ISAV was added directly to the water. For the tissue samples collected $2 \mathrm{~h}$ after addition of ISAV, RT-PCR positive results were found in the gill sample of 1 fish, while no samples were positive at $6 \mathrm{~h}$. At $24 \mathrm{~h}$, RT-PCR positive results were obtained in the gill, heart and mid-kidney samples from one fish, in heart, midkidney and intestine in a second fish and in the heart of
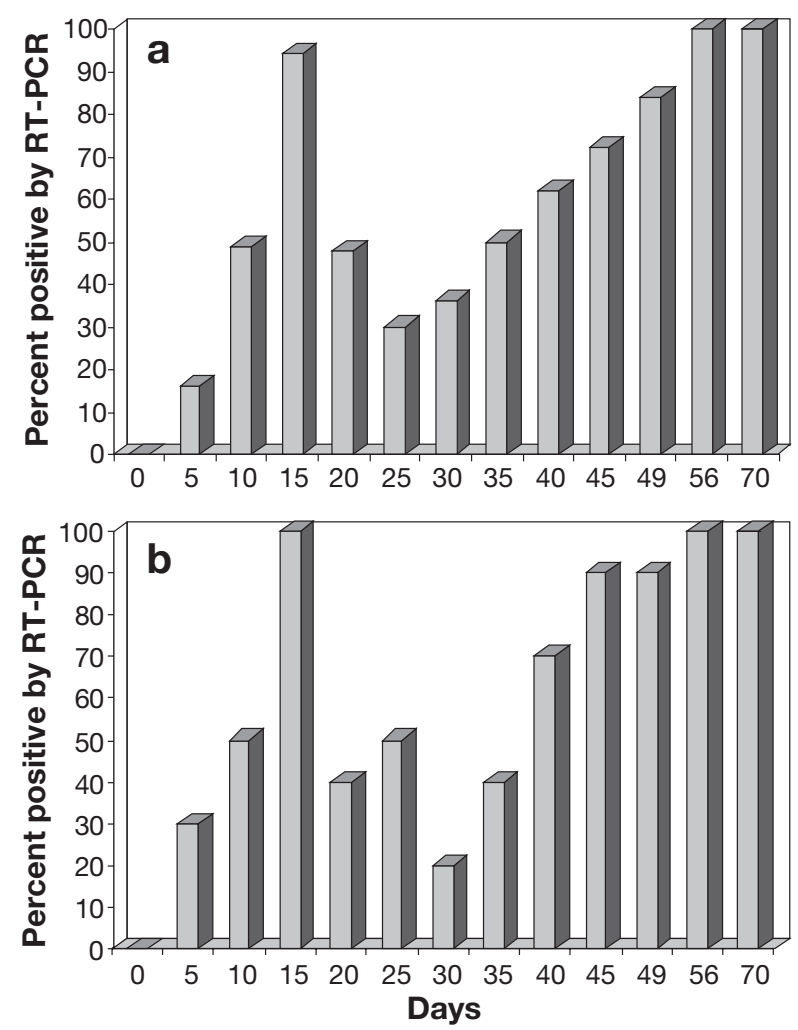

Fig. 3. Percentage of organs with positive RT-PCR results at various times during the experiment: (a) samples from all organs; (b) samples from the heart 
a third fish. At $48 \mathrm{~h}$, only the heart sample of 1 fish was positive and at $72 \mathrm{~h}$ no samples were positive.

Trial IV was conducted to simulate the transport of samples from the field to the diagnostic laboratory. All fish from Groups A, B, C and E yielded at least 1 positive RT-PCR, and from Groups B and E positive RT-PCRs were achieved for most tissue samples. For Groups D and F, the situation was rather different as only a few positive RT-PCRs were observed. For the Groups G to I, in which $0.9 \% \mathrm{NaCl}$ was added as transport medium for organ samples, the RT-PCR results in most samples were seen as smearing in addition to the band representing the ISAV specific sequence. In these groups some samples also produced DNA fragments with low density and some samples were negative.

\section{DISCUSSION}

Both the study of the pathogenesis of ISAV infection and the detection of ISAV infection in salmon require robust methods and thus benefit from the use of a sensitive RT-PCR. In the present study, the detection limit for the optimised, standard RT-PCR was estimated to be 0.01 to $0.1 \mathrm{TCID}_{50}$, implying a higher sensitivity than virus isolation. In our study, a laboratory-adapted virus strain was used, and perhaps the relative sensitivity would be even better when using RT-PCR in field cases for which the ISAV strain was not cell culture adapted. A comparison of the sensitivity of the fluorescent antibody test was not possible as no estimated detection limits for that test, when used for ISAV infection, are available (Falk et al. 1998). Several RT-PCR procedures for detection of ISAV have been described previously (Mjaaland et al. 1997, Devold et al. 2000, Griffiths \& Melville 2000). The main use of these RTPCRs has been in the confirmation of disease outbreaks in which the samples tested have a high load of ISAV and the sensitivity of the test has not been crucial (Rimstad et al. 1999). The optimisation of the procedure did affect the sensitivity as illustrated by the 100 -fold difference in the detection limit between the standard, optimised RT-PCR in which the RT and PCR were run in the same tube and the detection limit of methods in which these reactions were run in separate tubes. In the present procedure a relatively short amplicon, $155 \mathrm{bp}$, was chosen because a highly sensitive method was desirable. A procedure producing a longer amplicon spanning most of a genomic segment could have been more informative as to the viability of the virus, but the sensitivity of the method would have decreased accordingly. However, any RT-PCR only detects ISAV RNA, and does not give information on the infectivity of the virus.
Trial IV was performed to simulate different modes of transportation of samples from the fish farm to the diagnostic laboratory. The ISAV infection status was monitored prior to sample collection to ensure the presence of ISAV at the time of sampling. It was thus possible to compare the effect of different handling procedures on the RT-PCR performance prior to RNA extraction. The results showed that a normal transport process of whole fish did not strongly influence the result of the RT-PCR. This indicates that the ISAV RNA in tissue is rather stable and not severely degraded during regular transportation of whole fish. In Groups D and F, for which organs were dissected prior to the simulated transportation, however, most samples were RT-PCR negative. Compared with Group E, in which the organs were also dissected prior to the simulated transportation, but gave mostly positive RTPCR, the samples in Groups D and F were kept on ice for $24 \mathrm{~h}$ during the process. This difference indicates that the combination of dissection of samples and storage at 0 to $4^{\circ} \mathrm{C}$ for $24 \mathrm{~h}$ probably activated proteolytic activity and RNA degradation. A similar effect was observed when $0.9 \% \mathrm{NaCl}$ was added as transport medium. This procedure had a negative effect on the performance of the RT-PCR, and is thus not recommended. If the size of the fish prohibits the transport of whole fish to the diagnostic laboratory, then tissue samples should probably be treated like Group E; alternatively the use of RNase inhibiting transport media could be used. However, the potential toxicity of these solutions may be problematic in the transport process.

The present RT-PCR procedure was found to be robust, and the risk of contamination was kept at a low level by minimising the manual handling by running RT and PCR in the same tube, and performing single and not nested PCR.

In Trial I, the cumulative number of positives, for all organs tested, was in the range 57 to $63 \%$ of total samples tested for each organ. No organ was thus found to be better suited than others as a target for RTPCR. This finding demonstrated the importance of testing several organs for the presence of ISAV in regular RT-PCR diagnostic procedures. However, the heart was the only organ that gave positive RT-PCR results from one or more fish in all samplings, indicating the importance of testing this organ especially in the early stage of infection when most other organs yielded negative results.

The standard RT-PCR procedure enabled us to conduct experiments in which the route of entry of ISAV and the initial spread of ISAV in the fish could be studied. Both gills and/or oral entry are possible. After addition of ISAV to the water, one RT-PCR positive gill sample was found after $2 \mathrm{~h}$, and at $24 \mathrm{~h}$ one sample from each gill and intestine was found to be positive. 
Since the RT-PCR cannot distinguish between an active replicating virus or the passive transport of virus, both these infection routes were possible. At Day 5 in Trial I, however, $5 / 10$ gill samples were RT-PCR positive, while the heart was the only other positive organ. The gills are therefore important as the initial route of entry for ISAV, as has been indicated in earlier findings (Totland et al. 1996, Rimstad et al. 1999).

Twenty-four hours after the addition of virus to the water, positive RT-PCR results were obtained in heart and mid-kidney samples of $3 / 5$ and $2 / 5$ fish, respectively. This result indicates that viraemic spread of the virus occurs rapidly after infection. In the samplings at 48 and 72 h, 1 (heart) and no other positive organ samples were found, indicating that the virus load of the fish had decreased below the detection level of the RT-PCR. This may be caused by the innate immune response. In mammals and birds, Mx proteins with selective antiviral activity, especially against negativestranded RNA viruses, are important in the restriction of initial viral replication (Haller et al. 1979). The ISAV is a negative-stranded RNA virus, but the nature of the response restricting the ISAV replication is unknown. However, in Atlantic salmon, it has been shown that double-stranded RNA induces transcription of mRNA for $\mathrm{Mx}$, and that maximum expression in liver is seen $2 \mathrm{~d}$ post stimulation (Robertsen et al. 1997).

The fish in Trials I and II were infected by cohabitation and thus it is not possible to pinpoint the time of exposure to ISAV. However, the lack of positive RTPCR results before Day 5 after cohabitation with ISAVinjected fish could appear to contradict the results of Trial III unless the amount of ISAV shed from infected fish during the first days after infection is very low. The low virus shedding is consistent with the decrease in viral load shortly after infection as observed in Trial III. Again, this speculation suggests that the innate immune response affetcs ISAV replication in situ.

After Day 5, there was a marked increase in the total number of RT-PCR positive organs; the increase peaked at Day 15 with $94 \%$ positive. The early peak indicates that after the initial drop in viral load in a primary infection the virus spreads and replicates rapidly in the fish. The rapid spread and replication are made possible by the large presence of target cells, i.e. endothelial cells (Hovland et al. 1994). A decrease in the viral load followed the peak at Day 15 and a minimum viral load of $30 \%$ RT-PCR positive samples was found at Day 25. This drop was possibly due to both innate and, considering the time after exposure, specific immune responses inhibiting the replication of the virus. The virus load increased again after the minimum at Day 25, and remained at $100 \%$ RT-PCR positive samples after Day 56, producing a 2-phase curve of the viral load. This 2-phase curve was also observed for the individual organs, but with some variations between the organs, which was probably due to the limited number of tissues tested at each sampling.

In the tissue samples collected on Days 25, 35, 40 and 49 , individual fish were RT-PCR negative for all organs sampled, indicating that the fish had initially cleared the infection. The results from later samplings, when a final level of $100 \%$ positive samples occurred, indicate that reinfection was an important cause of ISAV infection for the fish population in the tanks. In the experiments, the buildup of a high infectious dose in the tank due to shedding of virus from infected fish was probably the cause of reinfection. The steady increase in viral load, combined with the observed $100 \%$ mortality of fish not collected during the experiment, indicated that a protective immune response was not induced. However, the infectious dose to which the fish were exposed in the tanks may have been very high and thus the cause of the observed lack of protection. The initial protective response that cleared the infection in some fish occurred at Day 25 of the experiment or before, when the viral load in the tank most likely was rather low. However, the titre of ISAV in the tank water was not monitored.

In conclusion, our findings support the suggestion that the gills are the major route of entry of ISAV in Atlantic salmon. After entry, the viral load displays an initial decline before rapid replication and dispersion occurs. This phase of early replication is followed by a temporary decrease in the viral load, which is possibly a consequence of the host's immune response. However, in our experiments the fish did not clear the virus, and a second increase in viral replication followed, that continued to the terminal stage of ISA, which may be attributed to reinfection from cohabitant fish.

Acknowledgements. The technical assistance of Lise Berven is greatly appreciated. This study was supported by grant no. 118549/121 from the Norwegian Research Council and from GenoMar asa.

\section{LITERATURE CITED}

Devold M, Krossoy B, Aspehaug V, Nylund A (2000) Use of RT-PCR for diagnosis of infectious salmon anaemia virus (ISAV) in carrier sea trout Salmo trutta after experimental infection. Dis Aquat Org 40:9-18

Evensen O, Thorud KE, Olsen YA (1991) A morphological study of the gross and light microscopic lesions of infectious anaemia in Atlantic salmon (Salmo salar). Res Vet Sci 51:215-222

Falk K, Dannevig BH (1995) Demonstration of infectious salmon anaemia (ISA) viral antigens in cell cultures and tissue sections. Vet Res 26:499-504

Falk K, Press CM, Landsverk T, Dannevig BH (1995) Spleen and kidney of Atlantic salmon (Salmo salar L.) show histochemical changes early in the course of experimentally 
induced infectious salmon anaemia (ISA). Vet Immunol Immunopathol 49:115-126

Falk K, Namork E, Rimstad E, Mjaaland S, Dannevig BH (1997) Characterization of infectious salmon anemia virus, an orthomyxo-like virus isolated from Atlantic salmon (Salmo salar L.). J Virol 71:9016-9023

Falk K, Namork E, Dannevig BH (1998) Characterization and applications of a monoclonal antibody against infectious salmon anaemia virus. Dis Aquat Org 34:77-85

Griffiths SG, Melville KJ (2000) Non-lethal detection of ISAV in Atlantic salmon by RT-PCR using serum and mucus samples. Bull Eur Fish Pathol 20:157-162

Haller O, Arnheiter H, Gresser I, Lindenmann J (1979) Genetically determined, interferon-dependent resistance to influenza virus in mice. J Exp Med 149:601-612

Hovland T, Nylund A, Watanabe K, Endresen C (1994) Observation of infectious salmon anemia virus in Atlantic salmon, Salmo salar L. J Fish Dis 17:291-296

Krossoy B, Hordvik I, Nilsen F, Nylund A, Endresen C (1999) The putative polymerase sequence of infectious salmon anemia virus suggests a new genus within the Orthomyxoviridae. J Virol 73:2136-2142

Mjaaland S, Rimstad E, Falk K, Dannevig BH (1997) Genomic characterization of the virus causing infectious salmon anemia in Atlantic salmon (Salmo salar L.): an orthomyxolike virus in a teleost. J Virol 71:7681-7686

Mullins JE, Groman D, Wodowska D (1998) Infectious samon anaemia in salt water Atlantic salmon (Salmo salar L.) in New Brunswick, Canada. Bull Eur Fish Pathol 18: $110-114$

Nylund A, Jakobsen P (1995) Sea-trout as a carrier of infectious salmon anemia virus. J Fish Biol 47:174-176

Editorial responsibility: Jo-Ann Leong,

Corvallis, Oregon, USA
Rimstad E, Falk K, Mikalsen AB, Teig A (1999) Time course tissue distribution of infectious salmon anaemia virus in experimentally infected Atlantic salmon Salmo salar. Dis Aquat Org 36:107-112

Rimstad E, Mjaaland S, Snow M, Mikalsen AB, Cunningham CO (2001) Characterisation of the genomic segment of infectious salmon anemia virus that encodes the putative hemagglutinin. J Virol 75:5352-5356

Robertsen B, Trobridge G, Leong JA (1997) Molecular cloning of double-stranded RNA inducible Mx genes from Atlantic salmon (Salmo salar L.). Dev Comp Immunol 21:397-412

Rodger HD, Richards RH (1998) Haemorrhagic smolt syndrome: a severe anaemic condition in farmed salmon in Scotland. Vet Rec 142:538-541

Rodger HD, Turnbull T, Muir F, Millar S, Richards RH (1998) Infectious salmon anaemia (ISA) in the United Kingdom. Bull Eur Fish Pathol 18:115-116

Sandvik T, Rimstad E, Mjaaland S (2000) The viral RNA 3'and 5 '-end structure and mRNA transcription of infectious salmon anaemia virus resemble those of influenza viruses. Arch Virol 145:1659-1669

Speilberg L, Evensen O, Dannevig BH (1995) A sequential study of the light and electron microscopic liver lesions of infectious anemia in Atlantic salmon (Salmo salar L.). Vet Pathol 32:466-478

Thorud KE, Djupvik HO (1988) Infectious anaemia in Atlantic salmon (Salmo salar L.). Bull Eur Fish Pathol 8:109-111

Totland GK, Hjeltnes BK, Flood PR (1996) Transmission of infectious salmon anaemia (ISA) through natural secretions and excretions from infected smelts of Atlantic salmon Salmo salar during their presymptomatic phase. Dis Aquat Org 26:25-31

Submitted: February 13, 2001; Accepted: May 23, 2001 Proofs received from author(s): November 23, 2001 